\title{
THE EMERGING ROLE OF BOTULINUM TOXIN IN THE TREATMENT OF OROFACIAL DISORDERS: LITERATURE UPDATE
}

\author{
SANTHOSH KUMAR MP* \\ Department of Oral and Maxillofacial Surgery, Saveetha Dental College and Hospital, Velappanchavadi, Chennai - 600 077, \\ Tamil Nadu, India. Email: santhoshsurgeon@gmail.com
}

Received: 03 January 2017, Revised and Accepted: 26 May 2017

\begin{abstract}
Botulinum toxin (BTX) is a lethal neurotoxin produced by Gram-positive anaerobic bacterium called Clostridium botulinum. It is the first toxin used for therapeutic purposes since 1989. BTX treatment is relatively safe and efficacious, less invasive, conservative, and the effects are faster and reversible. The purpose of this article is to review the literature regarding the applications of BTX in the treatment of various orofacial disorders, their mechanism of action, contraindications, and complications. From the recently published literature, it is clear that the role of BTX as a therapeutic agent for several conditions is expanding. With the training of BTX-A injection techniques and adequate knowledge about treatment protocols, general dentists can safely administer BTX injections. The ability to use Botox as an adjuvant and primary mode of the treatment for various maxillofacial disorders offers exciting treatment options for dentists and patients in the future.
\end{abstract}

Keywords: Botulinum toxin, Botulinum toxin A, Botox, Orofacial disorders, Temporomandibular disorders, Dentistry, Myofascial pain

(C) 2017 The Authors. Published by Innovare Academic Sciences Pvt Ltd. This is an open access article under the CC BY license (http://creativecommons. org/licenses/by/4. 0/) DOI: http://dx.doi.org/10.22159/ajpcr.2017.v10i9.16914

\section{INTRODUCTION}

Botulinum toxin (BTX) is a deadly neurotoxin produced by Grampositive anaerobic bacterium called Clostridium botulinum. Ingestion of contaminated food (canned or preserved) or wound infection releases bacterial toxin into the blood stream, eventually leading to severe symptoms of botulism such as vomiting, slurred speech, respiratory arrest, paralysis, and even death $[1,2]$. Botulinum, a natural protein and lethal neurotoxin is one of the most potent biological substances known which is used in bioterrorism as well [3]. It is the first toxin used for therapeutic purposes.

Justinus Kerner (1786-1862) gave the first complete description of clinical botulism, a life-threatening disease and called the toxin a "sausage poison," because it was observed that illness occurred after ingestion of spoiled sausage. In 1870, John Muller coined the term "botulism" (which means "sausage"). In 1949, Burgern was the first to discover that the toxin was able to block neuromuscular transmission. There are seven different toxin serotypes, namely, A, B, C, D, E, F and $G$, which differ in their potency, duration of action, and cellular target sites [4]. In human beings, botulism is mainly caused by types A, $\mathrm{B}, \mathrm{E}$, and rarely $\mathrm{F}$, whereas in animals it is caused by types $\mathrm{C}$ and $\mathrm{D}$. Commercially available variants are BTX-A and BTX-B, where BTX-A is the most commonly used toxin in medicine and dentistry. BTX-B is used in cases of resistance to BTX-A. BTX-E and BTX-F are used only for those individuals who do not respond to $\mathrm{A}$ and $\mathrm{B}$ due to clinical resistance or antibody formation. BTX-A is marketed worldwide under the name Botox (onabotulinum toxin A), Dysport in Europe, Xeomin in Germany, and Prosigne in China. BTX-B is marketed as Myobloc in the USA and Neurobloc in Europe.

Since 1989, BTX has been used for medical treatments but has recently become a popular innovative dental treatment option. Botox was approved by the US Food and Drug Administration (FDA) for the treatment of strabismus, blepharospasm, hemifacial spasm, facial glabellar lines, cervical dystonia, and axillary hyperhidrosis [5]. BTX-B has been approved by the FDA for the treatment of cervical dystonia. Since then BTX-A has been used for the treatment of various disorders in the orofacial region [6].

\section{CHEMICAL STRUCTURE}

BTX is synthesized as a single chain (150 kDa) and subsequently cleaved by host proteolytic enzymes into a di-chain molecule consisting of a $100 \mathrm{kDa}$ binding subunit and a $50 \mathrm{kDa}$ toxic subunit linked by a disulphide bond (Fig. 1). The light chain acts as a zinc endopeptidase with proteolytic activity located at the N-terminal end. The heavy chain provides cholinergic specificity and binding of the toxin to presynaptic receptors. This promotes translocation of the toxin across the endosomal membrane [7].

\section{PREPARATION OF BTX}

BTX is prepared by laboratory fermentation of the bacteria $C$. botulinum, which lyses and liberates the toxin into the culture. The toxin is then harvested, purified, crystallized with ammonium sulfate, diluted with human serum albumin, lyophilized, bottled in vials (sterile, vaccum dried powder form), and sealed for single use. Optimal $\mathrm{pH}$ of the solution is between 4.2 and 6.8, and vials should be stored in a freezer at or below $-5^{\circ} \mathrm{C}$. Preparations should be reconstituted with $1-5 \mathrm{~mL}$ of saline without preservatives just before use. Because Botox is easily denatured via bubbling or agitation, the diluent should be gently injected onto the inside of the wall of the vial. The reconstituted solution should be refrigerated at $2-8^{\circ} \mathrm{C}$ and used within $4 \mathrm{~h}$. The preferred syringe for injection is a $1.0 \mathrm{~mL}$ tuberculin syringe with a gauge of $26-30$ [8].

The potency of BTX is expressed as mouse units, with 1 mouse unit equivalent to the median lethal dose (LD 50) for a colony of $20 \mathrm{~g}$ Swiss Webster mice. Botox is dispensed in vials containing $100 \mathrm{U}$, while Dysport in vials containing 500 U. The relative potency of Botox units to Dysport units is approximately 1:4. BTX-B (Myobloc/Neurobloc) is available in vials of $2500 \mathrm{U} / 0.5 \mathrm{~mL}, 5000 \mathrm{U} / \mathrm{mL}$, or 10,000 U/2.0 mL. Its relative potency to Botox is 50-125 $\mathrm{U}$ of Myobloc to $1 \mathrm{U}$ of Botox. This product does not require reconstitution and is stable for up to 21 months in a refrigerator. Botox produces dose-dependant paralysis. When compared with BTX-B, BTX-A causes less pain during injection, longer duration of action, and more predictable diffusion patterns. The usual maximum total recommended therapeutic dose at an injection session in the dental office is about 80-100 U. Cosmetic dosages are less 
than the therapeutic dose. The human lethal dose is estimated to be approximately $3000 \mathrm{U}$. Thus, clinical dose can be given safely without a fatal overdose complication. The treatment dose varies for each brand of toxin and different parts of the body.

\section{ADMINISTRATION OF BTX}

It is injected either intramuscular, intradermal, intraglandular or into the affected area depending on the condition to be treated. Intramuscular

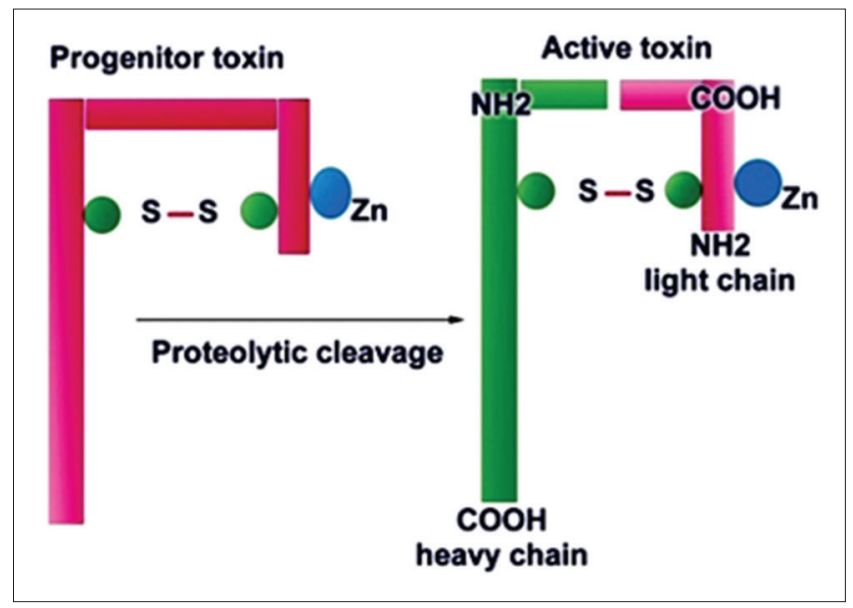

Fig. 1: Chemical structure of botulinum toxin
BTX injections are accomplished via a single-point or a skewered method with the needle inserted parallel to the plane of the muscle, and the injection is performed while the needle is carefully withdrawn. Care should be taken to space injections about $1-2 \mathrm{~cm}$ apart and to avoid injecting into muscles where paralysis is not desired [9]. BTX diffuses up to $10 \mathrm{~mm}$ into the adjoining areas, so a thorough knowledge of related anatomy is necessary to prevent undesirable effects. Gently pinching the muscle during injection may help reduce pain and ensure superficial placement of the drug. Topical anesthetic or ice may also be used to reduce pain during injection. Pressure with gauze immediately after injection is advisable to prevent bleeding and bruising and massaging the area after the injection is not recommended to prevent the unwanted diffusion of the toxin into adjacent muscles [10]. Strenuous physical activity should be avoided for 1 day after treatment. Injections are spaced out for a minimum of 3 months to minimize the risk of antibody formation to the protein, which would prevent BTX from working the subsequent time. Injections can administered with the help of electromyography (EMG) or ultrasound guidance for deeper muscles and joints. Topical formulations of BTX-A are also used for treating axillary hyperhidrosis with promising results.

\section{MECHANISM OF ACTION}

In the blood, the toxin targets peripheral neurons of the central nervous system (CNS) and binds to ganglioside receptors on the neuronal surface via the large subunit. Changes in $\mathrm{pH}$ at the neuronal surface mediate penetration of the membrane and passage of the small subunit into the neuron. The small subunit of the protein possesses a
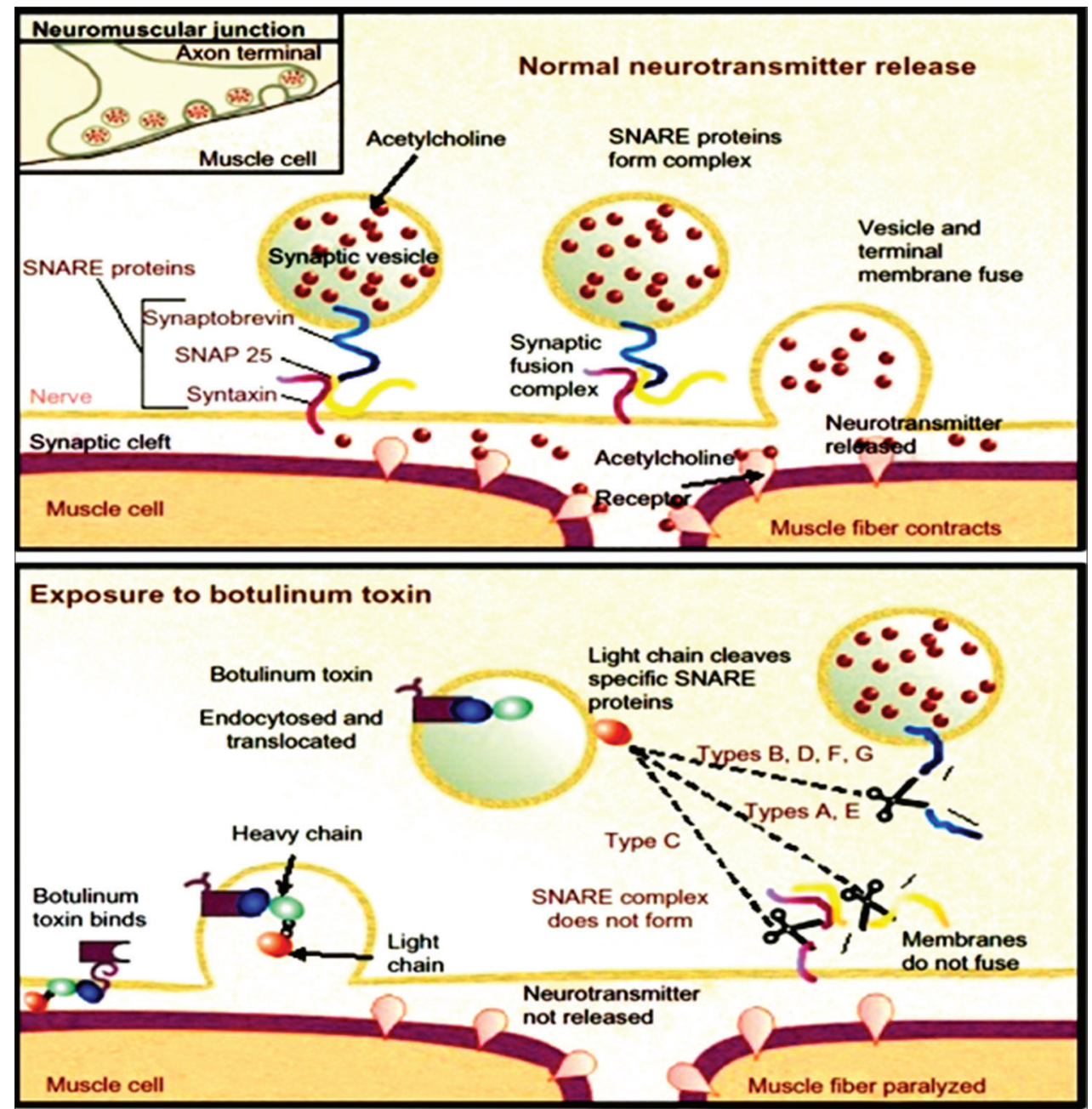

Fig. 2: Mechanism of action of botulinum toxin 
metalloprotease activity which cleaves components of the neuronal SNARE complex (Fig. 2). This complex is implicated in releasing neurotransmitter, acetylcholine when released depolarizes the motor end plates of the muscle thereby causing muscle contraction. Inhibition of this release leads to abolition of stimulatory activity of the neuron. This lack of stimulatory activity can cause paralysis, a major side effect of BTX administration.

Thus, BTX inhibits the release of acetylcholine from the presynaptic nerve terminal effectively and will either reduce the intensity of the contraction of the muscle or will eliminate the contraction altogether, depending on the dosage used. Thus, Botox causes a temporary muscle paralysis which lasts up to 3 months. Gradually, the muscle returns to its full function with no side effects as the muscle initiates new acetylcholine receptors, and the growth of branches from the neurons to form new synaptic contacts [11]. The toxin has also been shown to block acetylcholine release at parasympathetic nerve terminals. The clinical effects appear between 1 and 3 days after administration of BTX, and the maximum effects occur after 1-2 weeks, which then stabilizes to a moderate level until complete recovery of the nerve in approximately 3 months [12]. BTX does not inhibit the production of acetylcholine, and therefore, motor function is recovered by subsequent motor axon outgrowth [13].

Repeated treatments and increasing dosage with Botox have been shown to cause atrophy of the underlying muscles, usually leading to longer resolution of the problem. The antinociceptive and analgesic properties of BTX-A are also much discussed in the literature and have suggested that the BTX-A can play an independent role in peripheral nociceptors by blocking the release of certain neurotransmitters such as substance $\mathrm{P}$, glutamate, and calcitonin gene-related peptide [14]. Resistance is most likely associated with increased doses and frequency of treatment sessions $[15,16]$. Repeat doses of $300 \mathrm{U}$ and above have been associated with resistance [17]. Hence, treatment should be started with the minimal dose required and can be gradually increased. Injections are spaced out for a minimum of 3 months to minimize the risk of antibody formation to the protein, which would prevent Botox from working the subsequent time. The use of other serotypes (F or B) may benefit those who have devolved antibody resistance [18]

\section{CLINICAL APPLICATIONS OF BTX IN THE OROFACIAL REGION}

\section{Cosmetic applications}

Facial wrinkles occur naturally with due to pull off the skin by the underlying musculature, but becomes more prominent with aging and are unesthetic [19]. Botox has been approved for treating these hyperfunctional facial lines. When injected, it weakens the underlying muscles and is used worldwide successfully for treating glabellar (frown) lines, frontalis and lateral canthal lines (crow's feet), platysma bands, perioral lines, mentalis wrinkling, lower eyelid orbicularis hypertrophy, and vertical lip rhytids (lipstick lines) [20,21]. It is also used to treat hypertrophic scars and keloid with good results. Botox used in conjunction with dermal fillers have proved to be very beneficial for the correction of facial wrinkles [22,23]. BTX-A and dermal fillers have been used to provide immediate volume to black triangles formed due to loss or inadequate interpapillary tissue in the oral cavity [24,25].

\section{Therapeutic applications Gummy smile}

The gummy smile is characterized by a marked gingival exposure on smiling of more than $3 \mathrm{~mm}$. In the gummy smile caused by muscle hyperfunction, the BTX is injected into the lip elevator muscles thereby causing paralysis of them and resulting in less gingival display. It is the first preferred method in such cases due to ease and safety of applications, rapid effect, and more conservative method compared to surgical procedures (myectomy or Le Fort I osteotomy). Irineu presented a case of gummy smile successfully treated with BTX and showed that better results could be obtained with BTX either alone or as an adjuvant therapy to gingival resection surgery [26]. Several authors have demonstrated that BTX-A injections can be used successfully for treating gummy smiles [27-32]

\section{Temporomandibular disorders (TMD)}

TMD is a term which includes not only disorders of the temporomandibular joint (TMJ) but also includes a wide range of disturbances associated with the function of the masticatory system. TMDs may be myofascial (those related to muscles themselves) or arthrogenic (those related to TMJ) or both of them, but the majority of TMDs include a myogenic component, in which hyperactivity of the masticatory muscles are present [33]. Hence by directing treatment at the muscular component of TMD, therapeutic gains can be achieved. TMD symptoms can include jaw pain, neck pain, facial pain, difficulty with jaw opening, earaches, headaches, pain behind the eyes, jaw joint popping and clicking, dizziness, and difficulty chewing food or occluding the teeth. TMD are considered the major cause of pain in the orofacial region [34]. It has been shown that BTX injections can be the least invasive mode, which can provide relief of intractable symptoms in patients who have failed to show any improvement with the conventional modalities of treatment $[35,36]$. Injecting measured doses of BTX into specific sites (3-5 sites/muscle) in the major muscles of mastication can achieve sufficient masticatory muscle relaxation $[37,38]$. Although no definite protocol has been proposed, various case reports have recorded significantly decreased pain, and improved function and mouth opening at doses ranging from 25 to $150 \mathrm{U}$ of Botox injected intramuscularly into temporalis and masseter muscles for treating TMD [39].

In a study conducted by Freund et al. on 46 patients suffering from TMD, it was found that with150 U injections of BTX to the temporalis and masseter muscles; there was a remarkable improvement in mouth opening as there was a reduction in pain over masticatory muscles [40]. Lee et al. evaluated the effect of BTX injections on pain in six patients with limited mouth opening due to TMD. In all of their patient's symptoms subsided without any adverse effects during the 5-12 months follow-up period [41]. BTX injections have been used effectively for the treatment of masticatory muscle hypertonicity and parafunction [42]. The treatment protocol according to Katz included one injection of BTX $7.5 \mathrm{U}$ bilaterally into the anterior fibers of each temporalis muscle, and additional injections of $2.5 \mathrm{U}$ are given into the middle and posterior third of the temporalis muscles in the most severe cases. Masseter muscle is treated with $5 \mathrm{U}$ injections. [42]. Zhang et al. in their study concluded that BTX-A has obvious advantages for the treatment of TMD in terms of reducing the occlusal forces, but psychological intervention plays an important part of the treatment [43]. Park et al. found that Masseter muscle activity as measured by EMG was immediately decreased after a BTX-A injection [44]. There is strong evidence that BTX is a valuable clinical tool in the management of the myofascial component of temporomandibular disorders. The temporalis and masseter muscles are always treated bilaterally even if only one side of the face is involved.

\section{Bruxism}

Bruxism refers to both clenching and grinding of the teeth. Etiology is multifactorial and has a psychologic component involved. Bruxism can affect both TMJ and masticatory muscles. Bruxism destroys healthy dentition, exacerbates periodontal disease, causes TMD and ultimately leading to headaches and facial pain. Patients with chronic bruxism can have difficulty in speaking, chewing, swallowing and restricted mouth opening. BTX-A injections have been used to treat patients with parafunctional habits like bruxism by injecting into the flexor muscles of mandible which resulted in the relaxation of muscles in most of the cases. Bilateral injections of BTX-A in the dose range of 25-100 U per side into the masseter and temporalis muscles have provided resolutions of the symptoms of bruxism. BTX-A injections by removing bruxism element reduce facial pain, TMD symptoms and can significantly help the other associated treatments of periodontal disease [45]. This has also been proven useful in sleep bruxism $[46,47]$. 
Van Zandijcke and Marchau [48] described the successful treatment of a brain-injured patient with severe bruxism with $100 \mathrm{U}$ of BTX-A injections to the temporalis and masseter muscles and reported marked reduction in bruxism during the recovery period from coma. Tan and Jankovic [49] treated 18 patients with a history of severe bruxism by injecting BTX into the masseter muscle with mean dose of $61.7 \mathrm{U} /$ side (range 25-100 U) and obtained a total duration of therapeutic response of 19 weeks. Maaytah et al. [50] reported that BTX injection in the masseter muscles is an effective and safe means of intervention in cases of severe post-traumatic bruxism. It may be the only practical intervention available during the period of severe bruxism seen after brain injury when the patient is unable to cooperate. Ivanhoe et al. reported success with a $200 \mathrm{U}$ dose of BTX-A for severe bruxism in a patient with brain injury [51].

\section{Masseter muscle hypertrophy}

It is the unilateral or bilateral enlargement of the masseter muscles, which is mostly associated with clenching and bruxism. Other causes are anatomical asymmetry of the jaw, habitual asymmetric use of the jaw, or congenital malformations. This condition is commonly treated with Botox injections into masseter muscle [52], which thins the muscle and reduces the intensity of contraction of masseter muscle unlike surgical excision in which muscle bulk is reduced permanently. Recurrence of this condition is common in 6 months with BTX, as it reduces muscle volume only temporarily thereby making repeat injections necessary [53]. In a clinical trial, the injection of $30 \mathrm{U}$ per side of BTX into the masseter muscles resulted in a sustained reduction of gross masseter size (maximum reduction 35.4\%) [54]. Various clinical trials [55-57] reported that injections of BTX into the masseter muscles resulted in a sustained reduction of masseter hyperactivity. With BTX-A injections good, facial contour was achieved [58,59] and several cases were treated successfully [60]. Similarly, temporalis muscle hypertrophy can be treated with BTX injections [61].

\section{Myofascial pain}

TMD are considered a subgroup of musculoskeletal and rheumatologic disorders and represent the main cause of nondental pain in the orofacial region. For facial pain and TMD cases, BTX-A can be generally applied to a number of muscles of facial expression and mastication [62]. The FDA has approved BTX-A as a primary treatment for migraine and facial pain using a treatment protocol involving the muscles. BTX-A injections resulted in relief of pain in facial muscles in 90 percent of patients who did not respond to traditional treatments [63]. EMG evaluations were also used to evaluate the effects of BTX-A on muscle activity of patients with myofascial pain, with or without disc displacement. The results showed a decrease of muscle potential action of the masseter in the evaluation after 14 days and an increase in potential 28 days after the procedure. It was also found that the reduction of pain and improvement in psychological indices persisted at reassessment 28 days after the intervention [64].

BTX appears relatively safe and effective in treating cervical dystonia and chronic facial pain associated with masticatory hyperactivity [65]. Several studies have shown BTX-A injections to be effective in cases of chronic facial pain associated with muscle hyperactivity/bruxism [66-68]. Machado et al. [69], in their study, concluded further randomized controlled clinical trials, with representative samples and longer follow-up time, are required to assess the real effectiveness of BTX injections in the management of masticatory myofascial pain and muscular TMD. Injection of muscles with Botox has been reported to be effective for myofascial pain caused by trigger points [70]. Research has certainly shown that Botox and Dysport achieve successful treatment for many facial, TMD and oral dysfunctions which originate from the musculature [71]. Sidebottom et al. in their prospective study concluded that BTX is a valuable alternative second line treatment for masticatory myofascial pain when conservative measures have failed [72].

\section{Mandibular spasm}

It is a condition in which the elevator muscles of mandible are in a spasmatic condition resulting in restriction of mouth opening and pain during mandibular movements. Intramuscular Botox injections have resulted in relaxation of muscles, reducing inflammation of muscles and TMJ and the guarding response to pain thereby improving mouth opening. Several case reports have been published [73-76] describing the effectiveness of BTX-A in patients with hemimasticatory spasm, where all the patients responded positively to intramuscular Botox injections.

\section{Oromandibular dystonia (OMD)}

OMD is characterized by involuntary contraction of the masticatory and lower facial muscles causing unintentional opening and closing of the mouth in vertical, lateral, and protrusive directions. This will also result involuntarily chewing of the soft tissue inside the mouth often interfering with regular chewing and speaking. Although there is no cure for OMD, BTX injections have been the mainstay of treatment for most focal dystonia. Denervation of motor endplates has been proposed as the leading mechanism of action of BTX in dystonia, including OMD. Masseteric injection of Botox has been used for OMD as well as for plethora spasm which is often related conditions [77]. Literature on OMD treatment has reported improvement of symptoms with the use of BTX injections [78-82]. Over a 10-year period, Tan and Jankovic treated 162 patients with OMD by injecting BTX-A into the masseter muscles and/or the sub-mentalis complex, and improvement in chewing and speaking was reported in $67.9 \%$ of the patients [79].

\section{TMJ dislocation}

Recurrent dislocation of TMJ can occur due to OMD, epilepsy, stroke, and dyskinesias. BTX injection is specially indicated in patients in which conservative treatment has failed and surgery carries major risks. BTX-A has been used to treat recurrent TMJ dislocation by injecting into lateral pterygoid muscle in most of the cases and masseter muscle in some of the cases [83-86]. Bhogal et al. [87], in their review article, stated that mandibular dislocation when treated with BTX injection into lateral pterygoid muscles; the results lasted for a minimum of 3 months. Intramuscular BTX injection in lateral pterygoid muscle as an adjunct to arthrocentesis in the treatment of internal derangement of TMJ gave a good improvement of symptoms suggesting synergy between the two procedures [88].

\section{Salivary secretory disorders}

Sialorrhea

Excessive saliva production or the inability to hold saliva in the mouth can result in sialorrhea or drooling. Xerostomia is one of the manifestations of botulism, which led to the introduction of BTX to treat sialorrhea and drooling. BTX-A treated for sialorrhea associated with Parkinson's disease had a very favorable outcome when injected into parotids or both parotid and submandibular glands to inhibit the stimulation of cholinergic receptors [89-92]. Fuster et al. injected BTX into parotid submandibular gland or both with doses varying from 10 TO 100 units, which resulted in reduction in saliva production which lasted for 6 months [93]. This has to be done carefully, as too much will result in chewing difficulties, dysphagia and xerostomia. Botox is administered mostly only into parotid gland in a dose range of 30-70 U with a significant reduction in salivary flow observed in a month. However, the effects last only up to 3 months, and repeat injections are often necessary. BTX-A also had been treated with success for sialorrhea in patients with amyotrophic lateral sclerosis, cerebral palsy, and other neurological disorders which are caused by muscarinic type cholinergic hyperactivity [94-97].

It has also been used successfully in patients with post-traumatic and iatrogenic salivary sialoceles [98] and acute postparotidectomy salivary fistula [99]. Botox is useful in cases of drooling or salivary fistulas after oropharyngeal cancer surgery where temporary stopping of glandular secretory action is needed to promote healing [100]. Bartolo corradino 
et al. [101], in their study, injected 80-100 U of BTX -A preoperatively into major salivary glands for 43 oral cancer patients who underwent surgery and found that there was a considerable, temporary reduction of salivary secretion thereby avoiding the postoperative complications due to saliva stagnation and also helped in better healing and outcome of the surgery.

\section{Frey's syndrome}

Other uses of BTX are to treat auriculotemporal (Frey's) syndrome. However, its transient effectiveness (3-4 months) requires multiple injections. Intradermal injection of BTX into the affected area resulted in greater improvements in patients suffering from gustatory sweating, and the effects were long-lasting than intramuscular injections. [102]. Laccourreye et al., in a follow-up study of 33 Frey's syndrome patients treated with BTX, found recurrence rates of $27 \%$ in the $1^{\text {st }}$ year, $63 \%$ in the second, and $92 \%$ in the $3^{\text {rd }}$ year [103]. Guntinas-Lichius in his study demonstrated that using a higher concentration of BTX is more effective than a lower concentration in the treatment of Frey's syndrome [104]. Several other studies have also confirmed that BT is safe and efficacious treatment for gustatory sweating $[105,106]$.

Facial nerve palsy

Facial nerve palsy is a disfiguring condition for the patient and has been treated successfully with BTX. In patients with facial asymmetry, BTX injections into the normal side have been reported to result in an apparent symmetrical function of the face [107-109]. BTX-A is commonly used to treat facial synkinesis with marked improvement of facial symmetry at rest and during voluntary movements $[110,111]$. Hyperlacrimation (crocodile tears) which may occur after a facial palsy has been successfully treated by injecting BTX into lacrimal glands [112]. It has also been used to intentionally induce ptosis to protect cornea in facial palsy patients by injecting into the levator palpebrae superioris muscle [113]. There are also reports of BTX injections into lateral rectus and medial rectus muscles for treating third and sixth cranial nerve palsies with varied improvements.

Pain in head and neck region

BTX-A was found very effective in the management of various facial pain conditions such as tension headache, migraine, myofascial pain, trigeminal neuralgia and in post-operative wound pain including TMJ surgery, blowout fracture repair and reconstructive facial surgery. Botox 25-75 U injected into pericranial muscles relieves a headache by relaxing the overactive muscles by blocking nerve impulses that trigger contractions. For migraines Botox works by blocking the protein that carries the message of pain to the brain and relief typically takes effect in 2-3 weeks after injection and the longer the treatment duration, the better the pain relief [114]. Jennifer Warner reported pain relief in 25 patients with chronic neck pain after a single injection of Botox delivered to the affected neck muscle combined with standard physiotherapy [115]. BTX inhibits substance $P$ and is used in relieving excruciating pain associated with inflammation of trigeminal nerve, as it is an anti-inflammatory agent. Analgesic effect following BTX injections in orofacial pain are due to direct analgesic and neuromodulating mechanisms of BTX in the CNS, anti-inflammatory effects, and effects on the myofascial tender point [116]. Botox is also very useful in treating chronic pain syndrome [117]. Another study reported that BTX causes normalization of increased muscle spindle activity, decompression of afferent nociceptive neurons of muscular and vascular tissue [118].

\section{Trigeminal neuralgia}

Trigeminal neuralgia is frequently confused with dental pain and needs to be considered more often as a possible diagnosis when all other dental and muscle pathologies have been eliminated as the source of dental and facial pain. BTX-A use is increasing for trigeminal neuralgia cases and while the mechanism of action has not been well established, it has been a useful adjunct to treating these patients as primary or secondary treatment [119-121]. Ngeow and Nair described a persistent case of trigeminal neuralgia, when treated with 100 U BTX-A injection responded well immediately and the patient was completely relieved of pain for 5 months. Pain recurred later for which BTX injection was repeated and underwent neurosurgery after 1 year [122].

\section{Other uses}

Oral and maxillofacial trauma

In the treatment of various facial bone injuries, such as condylar, zygoma fractures, and BTX injections has proven to be useful in assisting postoperative wound healing by weakening/relaxing muscles, thereby reducing displacing forces on the fracture ends and obtain good immobilization if rigid fixation is not possible [123-126]. It also helps in reducing the number of plates required for stabilizing the bones. Facial laceration wound healing was better with BTX $[127,128]$.

\section{Implantology}

Parafunctional habits like bruxism or stress due to any excessive functional forces during osseointegration stage of implants can cause implant failure. Application of BTX relaxes masticatory muscles and helps in unimpeded osseointegration of implants especially in immediate load implant protocols [129]. However, not many studies demonstrate the beneficial effects of BTX use in dental implantology. Further randomized controlled trials are needed to evaluate their use in dental implantology [130]. Relapse is a problem after orthodontic treatment and/or orthognathic surgery and the root cause are the hyperactive muscles, e.g., mentalis muscle. BTX-A can reduce muscle contraction intensity, and over time, muscles can be trained to work normally. Similarly, in a patient receiving complete dentures BTX injections into muscles such as masseter, medial, and lateral pterygoid can be done for muscle training, thus enhancing in gradual adaptation of the orofacial musculature to the denture. In addition, according to Seok et al., the injection of BTX-A into the digastric muscle corrected the post-traumatic anterior open bite [131]. Chow et al. used BTX-A injections for treating ranula in 3 patients and achieved good results [132]

\section{Contraindications}

There are no absolute contraindications for BTX use. Relative contraindications include pregnancy, lactation, neuromuscular diseases (e.g., myasthenia gravis, amyotropic lateral sclerosis, EatonLambert syndrome, and Charcot disease), motor neuron disease, drug interactions (aminoglycosides, muscle relaxants, quinidine, calcium channel blockers, magnesium sulfate and polymyxin), allergy to any of the components of BTX-A or BTX-B (i.e. BTX, human albumin, saline, lactose, and sodium succinate), infection at injection site and psychologically unstable patients.

\section{Complications}

Local side effects are mild and include Pain, edema, headache, erythema, ecchymosis, blepharoptosis, and perioral muscular palsy. Other complications during therapeutic applications are dry eyes, mouth droop, lid edema, xerostomia, transient dysphagia, trismus, nasal regurgitation, nasal speech, blurred vision, dizziness, upset stomach, infection, neck weakness, voice changes, difficulty in chewing and breathing, risk of aspiration, recurrent jaw dislocation, dysarthria, salivary duct calculi, injury to branches of the facial nerve, facial muscle weakness, and facial asymmetry during movements. Systemic side effects are nausea, fatigue, headache, facial pain, flu-like symptoms, anxiety, itching, and transient weakness [1].

According to Cote et al. [133] in 2005, the adverse event reported to the FDA (1989-2003) after therapeutic and cosmetic use of BTX was 1437 cases. 217 serious adverse events were reported including 28 reported deaths; respiratory arrest, myocardial infarction, cerebrovascular accident, pulmonary embolism, and others [21]. All of them were related to therapeutic application rather than cosmetic purpose of the BTX. FDA issued a Black Box warning in 2009 because of the ability of BTX to migrate from injection site (systemic toxicity), that could lead to life-threatening symptoms of botulism (dysphagia and breathing difficulties) which is more likely to occur after intramuscular injections even with therapeutic doses. Botulism-like symptoms are 
muscle weakness, hoarseness or dysphonia, dysarthria, loss of bladder control, difficulty breathing, difficulty swallowing, double or blurred vision, and drooping eyelids which can occur anywhere from a day to several weeks after treatment at unrelated sites. However, safety of BTX-A in clinical uses has been well established [134]. Most of the adverse effects are linked to local tissue diffusion of BTX. Careful attention to drug dose, dilution, handling, storage, and site of injection are required for optimal treatment outcome and to minimize adverse effects.

\section{SUMMARY}

BTX is increasingly being used in medicine and dentistry and is associated with a few reversible adverse effects [128]. It is used in the field of oral and maxillofacial surgery for more than two decades. Botox applications are expanding in the treatment of various orofacial disorders. Its applications range from cosmetic to various therapeutic purposes such as temporomandibular disorders, salivary secretory disorders, hyperhidrosis, facial paralysis, orofacial pain, and implantology [135-139]. Even though numerous publications have reported successful outcomes after BTX application, they are mostly case reports and case series. There are only a few scientific reports with the high level of scientific evidence. Hence, more good quality clinical research needs to be carried out with randomized, controlled, blinded settings to understand the properties, clinical efficacy, and any associated long-term adverse effects. Treatment with BTX cannot be considered curative but a simple, safe, palliative, and symptomatic approach to the management of a problem. BTX treatments have shown to have a low risk of side effects and contraindications, are comparably cost effective, reversible and relatively safe, which makes this treatment choice popular among patients and dentists.

Dentists are highly knowledgeable regarding oral and facial anatomy, which seems reasonable for them to be at the forefront in providing these services, understanding limitations of treatment and having the ability to recognize and manage complications. As Botox treatment is technique, sensitive appropriate training is essential not only to administer the drug but also to deal with potential adverse effects. Benninger et al. [140] concluded from their study that BTX-A is an effective treatment for oral pathologies and dentists should be allowed to inject BTX-A based on their didactic and clinical anatomy courses and clinical curriculum. This study revealed the training of a general dentist appears to satisfy the basic science knowledge and clinical skills one would need to administer BTX-A injections to the head and neck region. Dentists worldwide are now treating patients with BTX-A for various oral and maxillofacial aesthetic and therapeutic purposes, and Botox injections are being integrated into dental treatment plans routinely [141,142]. But according to Al Hamdam et al., dentists in Saudi Arabia were hesitant in using BTX injections and derma fillers as they were lacking in knowledge and confidence regarding BTX injections and were worried about complications of BTX injections, which emphasizes the need for adequate training programs regarding BTX injections for the dentists [143]

\section{CONCLUSION}

BTX treatment is relatively safe and efficacious, less invasive, conservative and the effects are faster and reversible. It is used for both cosmetic and therapeutic purposes. The role of BTX as a therapeutic agent for several conditions is expanding. With training of BTX-A injection techniques and adequate knowledge about treatment protocols, general dentists can safely administer BTX injections. The ability to use Botox as an adjuvant and primary mode of treatment for various maxillofacial disorders offers exciting treatment options for dentists and patients in the future.

\section{REFERENCES}

1. Lu DW, Lippitz J. Complications of botulinum neurotoxin. Dis Mon 2009;55(4):198-211.

2. Cherington M. Botulism: Update and review. Semin Neurol
2004;24(2):155-63.

3. Arnon SS, Schechter R, Inglesby TV, Henderson DA, Bartlett JG, Ascher MS, et al. Botulinum toxin as a biological weapon: Medical and public health management. JAMA 2001;285(8):1059-70.

4. Welch MJ, Purkiss JR, Foster KA. Sensitivity of embryonic rat dorsal root ganglia neurons to Clostridium botulinum neurotoxins. Toxicon 2000;38(8):245-58

5. Scott $\mathrm{AB}$. Botulinum toxin injection into extraocular muscles as an alternative to strabismus surgery. Ophthalmology 1980;87(10):1044-9.

6. Scott AB. Development of botulinum toxin therapy. Dermatol Clin 2004;22(2):131-3, v.

7. Popoff MR, Bouvet P. Genetic characteristics of toxigenic Clostridia and toxin gene evolution. Toxicon 2013;75(1):63-89.

8. Melling J, Hambleton P, Shone CC. Clostridium botulinum toxins: Nature and preparation for clinical use. Eye (Lond) 1988;2:16-23.

9. Bakheit AM. The possible adverse effects of intramuscular botulinum toxin injections and their management. Curr Drug Saf 2006;1(3):271-9.

10. Schames J, Dov Prero Y, Schames D, Schames M, Gabriel W, Reed R. Uncontrollable distant effects of botulinum neurotoxin injections. J Calif Dent Assoc 2009;37:44-5.

11. Meunier FA, Schiavo G, Molgó J. Botulinum neurotoxins: From paralysis to recovery of functional neuromuscular transmission. J Physiol Paris 2002;96:105-13.

12. Blitzer A, Sulica L. Botulinum toxin: Basic science and clinical uses in otolaryngology. Laryngoscope 2001;111(2):218-26.

13. Kao I, Drachman DB, Price DL. Botulinum toxin: Mechanism of presynaptic blockade. Science 1976;193(4259):1256-8.

14. Dressler D, Adib Saberi F. Botulinum toxin: Mechanisms of action. Eur Neurol 2005;53(1):3-9.

15. Sankhla C, Jankovic J, Duane D. Variability of the immunologic and clinical response in dystonic patients immunoresistant to botulinum toxin injections. Mov Disord 1998;13(1):150-4.

16. Kessler KR, Skutta M, Benecke R. Long-term treatment of cervical dystonia with botulinum toxin A: Efficacy, safety, and antibody frequency. German Dystonia Study Group. J Neurol 1999;246(4):265-74.

17. Borodic G, Johnson E, Goodnough M, Schantz E. Botulinum toxin therapy, immunologic resistance, and problems with available materials. Neurology 1996;46(1):26-9.

18. Greene PE, Fahn S. Response to botulinum toxin F in seronegative botulinum toxin A - Resistant patients. Mov Disord 1996;11:181-4

19. Jaspers GW, Pijpe J, Jansma J. The use of botulinum toxin Type A in cosmetic facial procedures. Int J Oral Maxillofac Surg 2011;40(2):127-33.

20. Hoque A, McAndrew M. Use of botulinum toxin in dentistry. N Y State Dent J 2009;75(6):52-5.

21. de Maio M. Therapeutic uses of botulinum toxin: From facial palsy to autonomic disorders. Expert Opin Biol Ther 2008;8(6):791-8.

22. Carruthers J, Carruthers A. A prospective, randomized, parallel group study analyzing the effect of BTX-A (Botox) and nonanimal sourced hyaluronic acid (NASHA, Restylane) in combination compared with NASHA (Restylane) alone in severe glabellar rhytides in adult female subjects: Treatment of severe glabellar rhytides with a hyaluronic acid derivative compared with the derivative and BTX-A. Dermatol Surg 2003;29:802-9.

23. Patel MP, Talmor M, Nolan WB. Botox and collagen for glabellar furrows: Advantages of combination therapy. Ann Plast Surg 2004;52(5):442-7.

24. Amin V, Amin V, Swathi D, Jabir DA, Shetty P. Enhancing the smile with botox - Case report. Glob J Med Res 2014;13:15-8

25. Tezel A, Fredrickson GH. The science of hyaluronic acid dermal fillers. J Cosmet Laser Ther 2008;10(1):35-42.

26. Pedron IG. Gingival resection surgery complementation through botulinum toxin application at the management of gummy smile. RSBO 2015;12(4):389-93.

27. Gracco A, Tracey S. Botox and the gummy smile. Prog Orthod 2010;11(1):76-82.

28. Mangano A, Mangano A. Current strategies in the treatment of gummy smile using botulinum toxin Type A. Plast Reconstr Surg 2012;129(6):1015e.

29. Mazzuco R, Hexsel D. Gummy smile and botulinum toxin: A new approach based on the gingival exposure area. J Am Acad Dermatol 2010;63(6):1042-51.

30. Niamtu $\mathrm{J} 3^{\text {rd }}$. Botox injections for gummy smiles. Am $\mathrm{J}$ Orthod Dentofacial Orthop 2008;133(6):782-3.

31. Polo M. Botulinum toxin Type A in the treatment of excessive gingival display. Am J Orthod Dentofacial Orthop 2005;127(2):214-8. 
32. Sucupira E, Abramovitz A. A simplified method for smile enhancement: Botulinum toxin injection for gummy smile. Plast Reconstr Surg 2012;130(3):726-8.

33. Niamtu $\mathrm{J} 3^{\text {rd }}$. Botulinum toxin A: Areview of 1,085 oral and maxillofacial patient treatments. J Oral Maxillofac Surg 2003;61(3):317-24.

34. Makmacher L. Botulinum Toxin Frontline TMJ syndrome and Dental Therapeutic Treatment. Chicago USA.: Academy of General Dentistry; 2013.

35. Freund BJ, Schwartz M. Relief of tension-type headache symptoms in subjects with temporomandibular disorders treated with botulinum toxin-A. Headache 2002;42(10):1033-7.

36. Schwartz M, Freund B. Treatment of temporomandibular disorders with botulinum toxin. Clin J Pain 2002;18 6 Suppl: S198-203.

37. Kim HS, Yun PY, Kim YK. A clinical evaluation of botulinum toxin-a injections in the temporomandibular disorder treatment. Maxillofac Plast Reconstr Surg 2016;38(1):5

38. Chen YW, Chiu YW, Chen CY, Chuang SK. Botulinum toxin therapy for temporomandibular joint disorders: A systematic review of randomized controlled trials. Int J Oral Maxillofac Surg 2015;44:1018-26.

39. Song PC, Schwartz J, Blitzer A. The emerging role of botulinum toxin in the treatment of temporomandibular disorders. Oral Dis 2007;13(3):253-60.

40. Freund B, Schwartz M, Symington JM. The use of botulinium toxin for the treatment of temperomandibular disorders: Preliminary findings. J Oral Maxillofac Surg 1999;57(8):916-20.

41. Lee KM, Chow J, Hui E, Li W. Botulinum toxin Type A injection for the management of myofascial temporomandibular pain disorder. Asian J Oral Maxillofac Surg 2005;17(2):100-3.

42. Katz H. Botulinum toxins in dentistry - The new paradigm for masticatory muscle hypertonicity. Singapore Dent J 2005;27(1):7-12.

43. Zhang LD, Liu Q, Zou DR, Yu LF. Occlusal force characteristics of masseteric muscles after intramuscular injection of botulinum toxin A(BTX - A)for treatment of temporomandibular disorder. Br J Oral Maxillofac Surg 2016;54(7):736-40

44. Park SY, Park YW, Ji YJ, Park SW, Kim SG. Effects of a botulinum toxin Type A injection on the masseter muscle: An animal model study. Maxillofac Plast Reconstr Surg 2015;37:10

45. Long H, Liao Z, Wang Y, Liao L, Lai W. Efficacy of botulinum toxins on bruxism: An evidence-based review. Int Dent J 2012;62(1):1-5.

46. Lee SJ, McCall WD Jr, Kim YK, Chung SC, Chung JW. Effect of botulinum toxin injection on nocturnal bruxism: A randomized controlled trial. Am J Phys Med Rehabil 2010;89(1):16-23.

47. Shim YJ, Lee MK, Kato T, Park HU, Heo K, Kim ST. Effects of botulinum toxin on jaw motor events during sleep in sleep bruxism patients: A polysomnographic evaluation. J Clin Sleep Med 2014;10(3):291-8.

48. Van Zandijcke M, Marchau MM. Treatment of bruxism with botulinum toxin injections. J Neurol Neurosurg Psychiatry 1990;53(6):530

49. Tan EK, Jankovic J. Treating severe bruxism with botulinum toxin. J Am Dent Assoc 2000;131(2):211-6.

50. El Maaytah M, Jerjes W, Upile T, Swinson B, Hopper C, Ayliffe P. Bruxism secondary to brain injury treated with botulinum toxin-A: A case report. Head Face Med 2006;2:41.

51. Ivanhoe CB, Lai JM, Francisco GE. Bruxism after brain injury: Successful treatment with botulinum toxin-A. Arch Phys Med Rehabil 1997;78(11):1272-3.

52. Ludlow CL, Hallett M, Rhew K, Cole R, Shimizu T, Sakaguchi G, et al. Therapeutic use of type $\mathrm{F}$ botulinum toxin. N Engl J Med 1992;326(5):349-50.

53. Bentsianov B, Francis A, Blitzer A. Botulinum toxin treatment of temporomandibular disorders, masseteric hypertrophy, and cosmetic masseter reduction. Oper Tech Otolaryngol Head Neck Surg 2004;15:110-3.

54. Kim HJ, Yum KW, Lee SS, Heo MS, Seo K. Effects of botulinum toxin Type A on bilateral masseteric hypertrophy evaluated with computed tomographic measurement. Dermatol Surg 2003;29(5):484-9.

55. Al-Ahmad HT, Al-Qudah MA. The treatment of masseter hypertrophy with botulinum toxin Type A. Saudi Med J 2006;27(3):397-400.

56. Mandel L, Tharakan M. Treatment of unilateral masseteric hypertrophy with botulinum toxin: Case report. J Oral Maxillofac Surg 1999;57(8):1017-9.

57. Rijsdijk BA, van ES RJ, Zonneveld FW, Steenks MH, Koole R. Botulinum toxin Type A treatment of cosmetically disturbing masseteric hypertrophy. Ned Tijdschr Geneeskd 1998;142(10):529-32.

58. Lee CJ, Kim SG, Kim YJ, Han JY, Choi SH, Lee SI. Electrophysiologic change and facial contour following botulinum toxin A injection in square faces. Plast Reconstr Surg 2007;120(3):769-78.

59. Moore AP, Wood GD. The medical management of masseteric hypertrophy with botulinum toxin Type A. Br J Oral Maxillofac Surg 1994;32(1):26-8

60. Bas B, Ozan B, Muglali M, Celebi N. Treatment of masseteric hypertrophy with botulinum toxin: A report of two cases. Med Oral Patol Oral Cir Bucal 2010;15(4):e649-52.

61. Isaac AM. Unilateral temporalis muscle hypertrophy managed with botulinum toxin Type A. Br J Oral Maxillofac Surg 2000;38(5):571-2.

62. Kurtoglu C, Gur OH, Kurkcu M, Sertdemir Y, Guler-Uysal F, Uysal H. Effect of botulinum toxin-A in myofascial pain patients with or without functional disc displacement. J Oral Maxillofac Surg 2008;66(2):1644-51.

63. von Lindern JJ, Niederhagen B, Bergé S, Appel T. Type A botulinum toxin in the treatment of chronic facial pain associated with masticatory hyperactivity. J Oral Maxillofac Surg 2003;61(7):774-8

64. Ernberg M, Hedenberg-Magnusson B, List T, Svensson P. Efficacy of botulinum toxin Type A for treatment of persistent myofascial TMD pain: A randomized, controlled, double-blind multicenter study. Pain 2011;152(9):1988-96.

65. Ihde SK, Konstantinovic VS. The therapeutic use of botulinum toxin in cervical and maxillofacial conditions: An evidence-based review. Oral Surg Oral Med Oral Pathol Oral Radiol Endod 2007;104(2):e1-11.

66. Borodic GE, Acquadro MA. The use of botulinum toxin for the treatment of chronic facial pain. J Pain 2002;3(1):21-7.

67. Naumann M, Albanese A, Heinen F, Molenaers G, Relja M. Safety and efficacy of botulinum toxin Type A following long-term use. Eur J Neurol 2006;13 Suppl 4:35-40.

68. Guarda-Nardini L, Manfredini D, Salamone M, Salmaso L, Tonello S, Ferronato G. Efficacy of botulinum toxin in treating myofascial pain in bruxers: A controlled placebo pilot study. Cranio 2008;26(2):126-35.

69. Machado E, Santos LZ, Custódio LG, Cunali PA. Botulinum toxin for treating muscular temporomandibular disorders: A systematic review. Dent Press J Orthod 2012;17(6):167-71.

70. Jeynes LC, Gauci CA. Evidence for the use of botulinum toxin in the chronic pain setting - A review of the literature. Pain Pract 2008;8(4):269-76.

71. Soares A, Andriolo RB, Atallah AN, da Silva EM. Botulinum toxin for myofascial pain syndromes in adults. Cochrane Database Syst Rev 2014;7:CD007533.

72. Sidebottom AJ, Patel AA, Amin J. Botulinum injection for the management of myofascial pain in the masticatory muscles. A prospective outcome study. $\mathrm{Br} \mathrm{J}$ Oral Maxillofac Surg 2013;51(3):199-205.

73. Cersósimo MG, Bertoti A, Roca CU, Micheli F. Botulinum toxin in a case of hemimasticatory spasm with severe worsening during pregnancy. Clin Neuropharmacol 2004;27(1):6-8.

74. Auger RG, Litchy WJ, Cascino TL, Ahlskog JE. Hemimasticatory spasm: Clinical and electrophysiologic observations. Neurology 1992;42(12):2263-6.

75. Kim HJ, Jeon BS, Lee KW. Hemimasticatory spasm associated with localized scleroderma and facial hemiatrophy. Arch Dermotol 2000;57(4):576-80.

76. Kim YJ, Lee KS, Na JH, Kim BS, Ko YJ. A case of hemimasticatory spasm. J Korean Neurol Assoc 1994;12(1):175-8.

77. Bhidayasiri R, Cardoso F, Truong DD. Botulinum toxin in blepharospasm and oromandibular dystonia: Comparing different botulinum toxin preparations. Eur J Neurol 2006;13 Suppl 1:21-9.

78. Laskawi R, Rohrbach S. Oromandibular dystonia. Clinical forms, diagnosis and examples of therapy with botulinum toxin. Laryngorhinootologie 2001;80(12):708-13.

79. Tan EK, Jankovic J. Botulinum toxin A in patients with oromandibular dystonia: Long-term follow-up. Neurology 1999;53(9):2102-7.

80. Clark GT. The management of oromandibular motor disorders and facial spasms with injections of botulinum toxin. Phys Med Rehabil Clin N Am 2003;14(4):727-48.

81. Ferrín LM, Burguera JA, Diago MP, Diago MP. Oromandibular dystonia: A dental approach. Med Oral Patol Oral Cir Bucal 2010;15(1):e25-7.

82. Sinclair CF, Gurey LE, Blitzer A. Oromandibular dystonia: Long-term management with botulinum toxin. Laryngoscope 2013;123(12):3078-83

83. Moore A, Wood G. Medical treatment of recurrent temporomandibular joint dislocation using botulinum toxin. Br Dent $\mathrm{J}$ 1996;183(11-12):415-7.

84. Ziegler CM, Haag C, Mühling J. Treatment of recurrent temporomandibular joint dislocation with intramuscular botulinum 
toxin injection. Clin Oral Investig 2003;7(2):52-5.

85. Daelen B, Thorwirth V, Koch A. Treatment of recurrent dislocation of the temporomandibular joint with Type A botulinum toxin. Int J Oral Maxillofac Surg 1997;26(6):458-60.

86. Fu KY, Chen HM, Sun ZP, Zhang ZK, Ma XC. Long-term efficacy of botulinum toxin Type A for the treatment of habitual dislocation of the temporomandibular joint. Br J Oral Maxillofac Surg 2010;48(4):281-4.

87. Bhogal PS, Hutton A, Monaghan A. A review of the current uses of Botox for dentally-related procedures. Dent Update 2006;33(3):165-8.

88. Bakke M, Møller E, Werdelin LM, Dalager T, Kitai N, Kreiborg S. Treatment of severe temporomandibular joint clicking with botulinum toxin in the lateral pterygoid muscle in two cases of anterior disc displacement. Oral Surg Oral Med Oral Pathol Oral Radiol Endod 2005;100(6):693-700.

89. Friedman A, Potulska A. Quantitative assessment of parkinsonian sialorrhea and results of treatment with botulinum toxin. Parkinsonism Relat Disord 2001;7(4):329-32.

90. Lagalla G, Millevolte M, Capecci M, Provinciali L, Ceravolo MG. Botulinum toxin Type A for drooling in Parkinson's disease: A double-blind, randomized, placebo-controlled study. Mov Disord 2006;21(5):704-7.

91. Ondo WG, Hunter C, Moore W. A double-blind placebo-controlled trial of botulinum toxin B for sialorrhea in Parkinson's disease. Neurology 2004;62(1):37-40.

92. Dogu O, Apaydin D, Sevim S, Talas DU, Aral M. Ultrasound-guided versus 'blind' intraparotid injections of botulinum toxin-A for the treatment of sialorrhoea in patients with Parkinson's disease. Clin Neurol Neurosurg 2004;106(2):93-6.

93. Fuster Torres MA, Berini Aytés L, Gay Escoda C. Salivary gland application of botulinum toxin for the treatment of sialorrhea. Med Oral Patol Oral Cir Bucal 2007;12(7):E511-7.

94. Capaccio P, Torretta S, Osio M, Minorati D, Ottaviani F, Sambataro G, et al. Botulinum toxin therapy: A tempting tool in the management of salivary secretory disorders. Am J Otolaryngol 2008;29(5):333-8.

95. Svetel M, Vasic M, Dragasevic N, Pekmezovic T, Petrovic I, Kostic V. Botulinum toxin in the treatment of sialorrhea. Vojnosanit Pregl 2009;66(1):9-12

96. Benson J, Daugherty KK. Botulinum toxin A in the treatment of sialorrhea. Ann Pharmacother 2007;41(1):79-85.

97. Ellies M, Laskawi R, Rohrbach-Volland S, Arglebe C. Up-to-date report of botulinum toxin therapy in patients with drooling caused by different etiologies. J Oral Maxillofac Surg 2003;61(4):454-7.

98. Capaccio P, Cuccarini V, Benicchio V, Minorati D, Spadari F, Ottaviani F. Treatment of iatrogenic submandibular sialocele with botulinum toxin. Case report. Br J Oral Maxillofac Surg 2007;45(1):415-7.

99. Lim YC, Choi EC. Treatment of an acute salivary fistula after parotid surgery: Botulinum toxin Type A injection as primary treatment. Eur Arch Otorhinolaryngol 2008;265(2):243-5.

100. Corradino B, Di Lorenzo S, Mossuto C, Costa RP, Moschella F. Botulinum toxin in preparation of oral cavity for microsurgical reconstruction. Acta Otolaryngol 2010;130(1):156-60

101. Corradino B, Di Lorenzo S, Moschella F. Botulinum toxin A for oral cavity cancer patients: In microsurgical patients BTX injections in major salivary glands temporarily reduce salivary production and the risk of local complications related to saliva stagnation. Toxins (Basel) 2012;4(11):956-61.

102. Philouze P, Vertu D, Ceruse P. Bilateral gustatory sweating in the submandibular region after bilateral neck dissection successfully treated with botulinum toxin. $\mathrm{Br} \mathrm{J}$ Oral Maxillofac Surg 2014;52(8):761-3.

103. Laccourreye O, Akl E, Gutierrez-Fonseca R, Garcia D, Brasnu D, Bonan B. Recurrent gustatory sweating (Frey syndrome) after intracutaneous injection of botulinum toxin Type A: Incidence, management, and outcome. Arch Otolaryngol Head Neck Surg 1999;125(3):283-6.

104. Guntinas-Lichius O. Increased botulinum toxin Type A dosage is more effective in patients with Freys syndrome. Laryngoscope 2002;112(4):746-9.

105. Luna Ortiz K, Rascon Ortiz M, Sansón Riofrio JA, Villavicencio Valencia V, Mosqueda Taylor A. Control of Frey's syndrome in patients treated with botulinum toxin Type A. Med Oral Patol Oral Cir Bucal 2007;12(1):E79-84.

106. Sonny A, Sunder R, Trikha A. Botulinium toxin in the treatment of Frey's syndrome: A Brief report. Indian J Anaesth 2008;52:202-4.

107. Ahuja RB, Chatterjee P. Contemporary solutions for the treatment of facial nerve paralysis. Plast Reconstr Surg 2016;137(2):482e-3.
108. Garcia RM, Hadlock TA, Klebuc MJ, Simpson RL, Zenn MR, Marcus JR. Contemporary solutions for the treatment of facial nerve paralysis. Plast Reconstr Surg 2015;135(6):1025e-46.

109. Anthony VB. Asymmetrical smiles corrected by botulinum toxin serotype A. Am Soc Dermatol Surg 2007;33(S1):S32-6.

110. Armstrong MW, Mountain RE, Murray JA. Treatment of facial synkinesis and facial asymmetry with botulinum toxin Type A following facial nerve palsy. Clin Otolaryngol Allied Sci 1996;21(1):15-20.

111. Toffola ED, Furini F, Redaelli C, Prestifilippo E, Bejor M. Evaluation and treatment of synkinesis with botulinum toxin following facial nerve palsy. Disabil Rehabil 2010;32(17):1414-8.

112. Montoya FJ, Riddell CE, Caesar R, Hague S. Treatment of gustatory hyperlacrimation (crocodile tears) with injection of botulinum toxin into the lacrimal gland. Eye (Lond) 2002;16(6):705-9.

113. Ellis MF, Daniell M. An evaluation of the safety and efficacy of botulinum toxin Type A (BOTOX) when used to produce a protective ptosis. Clin Exp Ophthalmol 2001;29(6):394-9.

114. Silberstein S, Mathew N, Saper J, Jenkins S. Botulinum toxin Type A as a migraine preventive treatment. For the BOTOX Migraine Clinical Research Group. Headache 2000;40(6):445-50.

115. Clark GT, Stiles A, Lockerman LZ, Gross SG. A critical review of the use of botulinum toxin in orofacial pain disorders. Dent Clin N Am 2007;51(1):245-61

116. Junghans K, Rohrbach S, Ellies M, Laskawi R. Improvement of chronic facial pain and facial dyskinesia with the help of botulinum toxin application. Head Face Med 2007;3:32.

117. Rzany B, Ascher B, Fratila A, Monheit GD, Talarico S, Sterry W. Efficacy and safety of 3- and 5-injection patterns (30 and $50 \mathrm{U}$ ) of botulinum toxin A (Dysport) for the treatment of wrinkles in the glabella and the central forehead region. Arch Dermatol 2006;142(3):320-6.

118. Göbel H, Jost WH; Arbeitsgruppe Schmerz im Arbeitskreis Botulinumtoxin der Deutschen Gesellschaft für Neurologie. Botulinum toxin in specific pain therapy. Schmerz 2003;17(7):149-65.

119. Hu Y, Guan X, Fan L, Li M, Liao Y, Nie Z, et al. Therapeutic efficacy and safety of botulinum toxin Type $\mathrm{A}$ in trigeminal neuralgia: A systematic review. J Headache Pain 2013;14:72.

120. Guardiani E, Sadoughi B, Blitzer A, Sirois D. A new treatment paradigm for trigeminal neuralgia using botulinum toxin Type A. Laryngoscope 2014;124(2):413-7.

121. Bohluli B, Motamedi MH, Bagheri SC, Bayat M, Lassemi E, Navi F, et al. Use of botulinum toxin A for drug-refractory trigeminal neuralgia: Preliminary report. Oral Surg Oral Med Oral Pathol Oral Radiol Endod 2011;111(1):47-50.

122. Ngeow WC, Nair R. Injection of botulinum toxin Type A (Botox) into trigger zone of trigeminal neuralgia as a means to control pain. Oral Surg Oral Med Oral Pathol Oral Radiol Endodontol 2010;109(3):e47-50.

123. Akbay E, Cevik C, Damlar I, Altan A. Treatment of displaced mandibular condylar fracture with botulinum toxin A. Auris Nasus Larynx 2014;41(2):219-21.

124. Canter HI, Kayikcioglu A, Aksu M, Mavili ME. Botulinum toxin in closed treatment of mandibular condylar fracture. Ann Plast Surg 2007:58(5):474-8.

125. Jeong CH, Ryu JY, Lee WY, Kim HM. Simultaneous surgery for subcondylar fracture and prominent angle of the mandible. Maxillofac Plast Reconstr Surg 2015;37(1):26.

126. Kayikçioglu A, Erk Y, Mavili E, Vargel I, Ozgür F. Botulinum toxin in the treatment of zygomatic fractures. Plast Reconstr Surg 2003;111(1):341-6.

127. Zhang DZ, Liu XY, Xiao WL, Xu YX. Botulinum toxin Type A and the prevention of hypertrophic scars on the maxillofacial area and neck: A meta-analysis of randomized controlled trials. PLoS One 2016;11(3):e0151627

128. Reddy P, Gosavi D, Reddy S. Lifestyle drugs. Int J Pharm Pharm Sci 2012;4 Suppl 5:43-5

129. Ihde S. Therapeutic use of botulinum toxin in maintenance therapy in dental implantology. Implantology. 2005;14(2):56-61.

130. Ihde S. Prophylactic use of botulinum toxin in dental implantology. CMF Implement Dir 2007;1:29-34

131. Seok H, Park YT, Kim SG, Park YW. Correction of post-traumatic anterior open bite by injection of botulinum toxin Type A into the anterior belly of the digastric muscle: Case report. J Korean Assoc Oral Maxillofac Surg 2013;39(4):188-92.

132. Chow TL, Chan SW, Lam SH. Ranula successfully treated by botulinum toxin Type A: Report of 3 cases. Oral Surg Oral Med Oral Pathol Oral Radiol Endod 2008; 105:41-2.

133. Coté TR, Mohan AK, Polder JA, Walton MK, Braun MM. Botulinum 
toxin Type A injections: Adverse events reported to the US Food and Drug Administration in therapeutic and cosmetic cases. J Am Acad Dermatol 2005;53(3):407-15.

134. Naumann M, Jankovic J. Safety of botulinum toxin Type A: A systematic review and meta-analysis. Curr Med Res Opin 2004;20(7):981-90.

135. Vidya VS, Felicita AS. Efficacy of pharmacological agents in the treatment of temporomandibular joint disorder: A systematic review. Int J Pharm Pharm Sci 2015;7(4):54-8.

136. Gok G, Cox N, Bajwa J, Christodoulou D, Moody A, Howlett DC. Ultrasound-guided injection of botulinum toxin $\mathrm{A}$ into the submandibular gland in children and young adults with sialorrhoea. Br J Oral Maxillofac Surg 2013;51:231-3.

137. George KS, Kiani H, Witherow H. Effectiveness of botulinum toxin $\mathrm{B}$ in the treatment of drooling. Br J Oral Maxillofac Surg 2013;51(8):783-5.
138. Alodeani EA. Botulinum toxin Type A: An effective, safe and minimally invasive treatment option of axillary and palmar hyperhidrosis. Int J Pharm Pharm Sci 2016;8(7):237-40.

139. Mehdizadeh OB, Diels J, White WM Botulinum toxin in the treatment of facial paralysis. Facial Plast Surg Clin North Am 2016;24(1):11-20.

140. Benninger B, Ross A. Should dentists be allowed to administer botulinum toxin? Dentistry 2012;2:135.

141. Majid OW. Clinical use of botulinum toxins in oral and maxillofacial surgery. Int J Oral Maxillofac Surg 2010;39(3):197-207.

142. Berry MG, Stanek JJ. Botulinum neurotoxin A: A review. J Plast Reconstr Aesthet Surg 2012;65(10):1283-91.

143. Al Hamdan EM, Algheryafi AM, Al-Ghareeb FJ, Ashri NY. Knowledge and attitude of dentists towards the use of botulinum toxin and dermal fillers in dentistry, Riyadh, Saudi Arabia. J Cosmet Laser Ther 2013;15:46-54. 